\title{
ANALISIS FAKTOR PENENTU DAYA SAING KOMODITAS PANGAN DI PROVINSI JAWA TENGAH
}

\author{
Harini $^{1}$, Yunastiti Purwaningsih ${ }^{2}$, Malik Cahyadin ${ }^{3}$ \\ ${ }^{1,2,3}$ Fakultas Ekonomi dan Bisnis, Universitas Sebelas Maret \\ Email: yst_stm@yahoo.com, malikcahyadin@yahoo.com
}

\begin{abstract}
This study identifies and analyzes competitiveness factors of food commodities in Central Java. The research data covers primary data with 245 respondents of food commodities sellers. The research method was using the Analytic Hierarchy Process (AHP). AHP calculation results show that food competitivesness factors involve: a) the agricultural sector investment with a value of 0.28 ; $b$ ) agricultural infrastructure with a value of $0.24 ; c$ ) government program of food security and safety with a value of $0.20 ; d)$ government's active role in supervision of food with a value of 0.18 ; e) the accessibility of local food commodities with a value of 0.06; and f) the high demand for domestic food with a value of 0.05 .
\end{abstract}

Keywords: food commodities, competitiveness, AHP

JEL Classification: F10, F14

\section{PENDAHULUAN}

Daya saing merupakan salah satu indikator penting dalam perkembangan bisnis atau ekonomi. Namun demikian, penjelasan tentang daya saing bisa berbeda sesuai dengan aspek yang dijelaskan. Menurut Ambastha dan Momaya (2004) proses daya saing menjadi kunci dalam koordinasi proses manajemen seperti manajemen stratejik, manajemen sumberdaya manusia, manajemen teknologi, dan manajemen operasi. Secara empiris, bukti daya saing pada perusahaan makanan telah dilakukan oleh Fischer (2002); Halmai dan Elekes (2002); Cuevas (2004); Bodini dan Zanoli (2009); Bohari, Hin dan Fuad (2013); Seguin and Sweetland (2014); dan Eskandari et.al. (2015).

Fischer (2002) berpendapat bahwa produk makanan dan minuman yang diperdagangkan perlu dikaji lebih mendalam terutama dari aspek ko- nsumen. Hal ini disebabkan tidak hanya produk tersebut adalah produk konsumen tetapi juga menjadi pertimbangan dalam daya saing perusahaan makanan dan minuman. Salah satu pertimbangan faktor pembentuk daya saing perusahaan makanan dan minuman adalah risiko atas produk makan dan minuman dengan jarak distribusi yang jauh (antar negara) dan kebutuhan konsumen. Untuk itu, Halmai dan Elekes (2002) menyarankan bahwa analisis daya saing sektor pertanian melihat juga analisis harga, subsidi ekspor, dan proteksi impor.

Cuevas (2004) mempertimbangkan bahwa produk pertanian cenderung tergantung pada kondisi geografis, variasi lingkungan dan iklim, hama dan polusi. Untuk itu, integrasi bisnis produk pertanian perlu dilakukan mulai dari hulu sampai hilir. Kebijakan ini perlu dilakukan oleh semua negara berkembang untuk melindungi 
dan meningkatkan daya saing pertanian termasuk kesejahteraan pelaku usahanya. Salah satu bentuk usaha yang dapat didorong pada sektor pertanian adalah usaha kecil dan menengah (UKM). Menurut Bodinidan Zanoli (2009) UKM sektor pertanian perlu didorong untuk mampu bersaing di area pasar yang lebih luas. Untuk itu, para UKM tersebut memerlukan kemampuan proses bisnis yang handal dengan dukungan teknologi dan pemahaman akan konsumen sebagai target pasarnya. Hal ini juga yang diperlukan oleh semua perusahaan produk pertanian, termasuk produk halal (lihat Bohari, Hin dan Fuad; 2013): Seguin and Sweetland; 2014): dan Eskandari et.al.; 2015).

Penelitian empiris yang telah dijelaskan di atas menjadi pertimbangan untuk melakukan penelitian tentang daya saing komoditas pangan Jawa Tengah. Fokus penelitian ini adalah faktor penentu daya saing komoditas pangan. Komoditas pangan yang menjadi obyek penelitian meliputi Beras, Jagung, Kedelai, Daging Ayam, Daging Sapi, Ikan, dan Buah-buahan. Sementara itu, faktor penentu dirumuskan berdasarkan identifikasi faktorfaktor yang dapat mendorong daya saing komoditas pangan Jawa Tengah. Identifikasi faktor tersebut didasarkan pada penelitian terdahulu dalam penelitian ini. Hasil penelitian ini menunjukkan bahwa ada enam faktor pendorong daya saing komoditas pangan Jawa Tengah. Metode penentuan faktor tersebut menggunakan Analytic $\mathrm{Hi}$ erarchy Process (AHP).

\section{Permasalahan Penelitian}

Faktor penentu daya saing komoditas pangan perlu diteliti untuk mengetahui bagaimana daya saing tersebut terbentuk. Hal ini telah dilakukan oleh Fischer (2002); Cuevas (20-
04); Bodini dan Zanoli (2009); Bohari, Hin dan Fuad (2013); Seguin and Sweetland (2014); dan Eskandari et.al. (2015).

Berdasarkan penelitian tersebut maka penelitian ini akan fokus pada beberapa permasalahan penelitian sebagai berikut: Bagaimana perkembangan komoditas pangan di Jawa Tengah? Faktor apa saja yang menjadi penentu daya saing komoditas pangan Jawa Tengah?

\section{TINJAUAN PUSTAKA DAN HIPOTESIS}

Konsep Daya Saing mengacu pada beberapa pandangan ahli dengan sudut pandang/aspek yang berbedabeda (Vuković, Jovanović, dan Đukić; 2012: Aiginger, Bärenthaler-Sieber dan Vogel; 2013: Siudek dan Zawojska; 2014: Bris dan Caballero; 2016; dan Ketels; 2016). Menurut Vuković, Jovanović, dan Đukić (2012) konsep daya saing dapat dikaitkan dengan suatu kawasan/regional misal pendekatan Porter dan Krugman.

Pendekatan Porter menekankan pada aspek geografi/lokasi pada penentuan daya saing yang lebih dikenal dengan "diamond". Konsep tersebut memberikan gambaran bahwa geografi/lokasi dapat mendorong produktivitas, inovasi, dan ekspor. Sementara itu, Krugman lebih mengkaitkan antara keunggulan komparatif dan kompetitif pada aspek geografi/lokasi.

Aiginger, Bärenthaler-Sieber dan Vogel (2013) telah mengidentifikasi beberapa bentuk daya saing, yaitu: daya saing harga, daya saing kualitas, dan daya saing outcome. Penekanan masing-masing bentuk daya saing tersebut adalah:

1) Daya saing harga bermula dari adanya upaya terhadap efisiensi biaya usaha (pada suatu perusa- 
haan) terutama pada komponen upah, energi dan pajak.

2) Daya saing kualitas menekankan pada upaya pencapaian produktivitas usaha dan keberlanjutannya. Daya saing ini juga dapat dikaitkan dengan peranan teknologi dalam proses bisnis sehingga dapat juga disebut sebagai daya saing teknologi.

3) Daya saing outcome menekankan pada komposisi dan posisi neraca perdagangan dan pembayaran suatu negara. Dengan kata lain, daya saing ini tidak terlepas dari kondisi dan perkembangan indikator makroekonomi suatu negara.

Penjelasan secara lebih skematis tentang bentuk daya saing diatas dapat dilihat pada Gambar 1. Berdasarkan gambar tersebut dapat diketahui bahwa daya saing harga fokus pada aspek biaya dan produktivitas, daya saing kualitas fokus pada struktur dan kapabilitas, sedangkan daya saing outcome fokus pada indikator makroekonomi (tradisional) dan perspektif baru.

Gambar1. Bentuk-bentuk Daya Saing

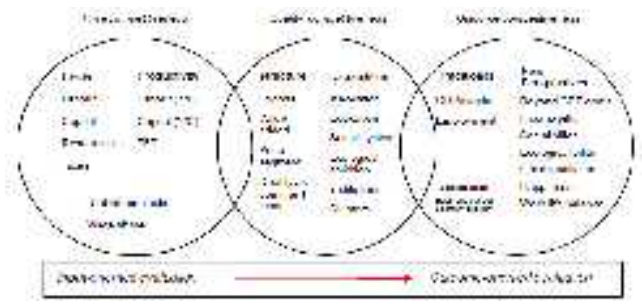

Sumber: Aiginger, Bärenthaler-Sieber dan Vogel (2013)

Daya saing yang dikaitkan dengan perdagangan komoditas pangan telah dijelaskan oleh Cahyadin dan Nihayah (2014); dan Harini, Purwaningsih, Cahyadin, dan Widiyanti (2015). Cahyadin dan Nihayah (2014) menjelaskan bahwa:

Tataniaga komoditas kebutuhan pokok sangat penting pe- ranannya karena menghubungkan pelaku antar agrobisnis dengan pelaku lainnya dalam sebuah sistem. Keberhasilan sebuah tataniaga, salah satunya apabila mampu menyalurkan barang kepada konsumennya.Tataniaga komoditas kebutuhan pokok di Indonesia sangat bervariatif tergantung komoditas serta regulasi yang diterapkan.

Sementara itu, Harini, Purwaningsih, Cahyadin, dan Widiyanti. (2015) telah mengidentifikasi perdagangan komoditas pangan di daerah Jawa Tengah dengan hasil, yaitu:

1) Pola perdagangan komoditas tanaman pangan di wilayah Provinsi Jawa Tengah menggunakan tiga tipe, yaitu: pembelian dari petani dan penjualan kepada konsumen akhir secara langsung, pembelian dari petani secara tidak langsung dan penjualan kepada konsumen akhir secara langsung, pembelian dari impor secara tidak langsung dan penjualan kepada konsumen akhir secara langsung.

2) Faktor internal tata niaga komoditas tanaman pangan antara lain ketersediaan barang sebagian besar dari produksi lokal dengan harga yang terjangkau, komoditas tanaman pangan tidak tahan lama dan kios jualan kurang tertata rapi. Sementara itu, faktor eksternal adalah komoditas ini merupakan kebutuhan pokok masyarakat, dan banyaknya pesaing.

3) Pemetaan tata niaga komoditas tanaman pangan di wilayah Provinsi Jawa Tengah menunjukkan bahwa ketersediaan barang berasal dari wilayah Provinsi Jawa 
Tengah, Jawa Timur, Jawa Barat, dan impor. Sementara itu, kebutuhan komoditas ini hanya untuk memenuhi permintaan konsumen lokal di wilayah Provinsi Jawa Tengah.

\section{METODE PENELITIAN}

Data yang digunakan dalam penelitian ini adalah data primer. Data tersebut diperoleh melalui survei kepada 245 pedagang komoditas pangan di wilayah Provinsi Jawa Tengah. Para pedagang tersebut ditetapkan dengan menggunakan metode sampel yaitu quota sampling. Fokus survei adalah melakukan penilaian dan prioritas faktor penentu daya saing komoditas pangan. Ada enam faktor yang akan dinilai dan ditentukan prioritasnya, yaitu: Investasi Sektor Pertanian; Infrastruktur Pertanian; Program Ketahanan dan Keamanan Pangan; Peran Aktif Pemerintah dalam Pengawasan Pangan; Aksesibilitas Komoditas Pangan Lokal; dan Tingginya Kebutuhan Pangan Dalam Negeri.

Metode analisis data yang digunakan adalah Analytic Hierarchy Process (AHP). Secara konseptual, metode AHP mengacu pada Saaty (2008). Sementara itu, secara teknikal penggunaan metode AHP pada penelitian ini menggunakan kuisioner dengan skala preferensi $1-9$. Penjelasan skala tersebut adalah: $1=$ sama penting, 2 = antara sama penting dan sedikit lebih penting, $3=$ sedikit lebih penting, $4=$ antara sedikit lebih penting dan lebih penting, $5=$ lebih penting, $6=$ antara lebih penting dan sangat lebih penting, 7 = sangat lebih penting, $8=$ antara sangat lebih penting dan mutlak lebih penting, $9=$ mutlak lebih penting. Pada responden akan menentukan preferensi mereka terhadap faktor penentu daya saing ko- moditas pangan Jawa Tengah berdasarkan skala tersebut.

\section{ANALISIS DATA DAN PEMB-} AHASAN

\section{Perkembangan Komoditas Pangan Jawa Tengah}

Perkembangan tanaman pangan dapat dilihat dari nilai outputnya. Nilai ini apabila diwakili oleh hasil perhitungan terhadap nilai pasar dapat menggunakan data nilai PDB subsektor tanaman pangan. Penjelasan tersebut dapat dilihat pada Tabel 1 . Berdasarkan tabel ini dapat diketahui bahwa:

1) Nilai PDB sektor pertanian, peternakan, perburuan, dan jasa pertanian pada triwulan I - III tahun 2014 cenderung meningkat sedangkan pada triwulan IV tahun 2014 cenderung menurun.

2) Nilai PDB subsektor tanaman pangan pada triwulan I - IV tahun 2014 cenderung berfluktuasi. Secara total nilai PDB subsektor ini berada pada urutan nomor dua setelah subsektor tanaman perkebunan.

3) Nilai PDB subsektor tanaman hortikultura pada triwulan I - III tahun 2014 cenderung meningkat sedangkan pada triwulan IV tahun 2014 cenderung menurun.

4) Nilai PDB subsektor tanaman perkebunan pada triwulan I - III tahun 2014 cenderung meningkat sedangkan pada triwulan IV tahun 2014 cenderung menurun. Secara total nilai PDB subsektor ini berada pada peringkat pertama terhadap pembentukan nilai PDB sektor pertanian di Indonesia.

5) Nilai PDB subsektor peternakan pada triwulan I - IV cenderung meningkat. 
6) Nilai PDB subsektor jasa pertanian dan perburuan selama triwulan I - IV tahun 2014 cenderung berfluktuasi.

Nilai PDB suksektor tanaman pangan yang cenderung berfluktuasi terkait erat dengan periode musim panen dan musim tanam. Selain itu, faktor perubahan iklim yang berakibat pada berkurangnya jumlah produksi/hasil panen juga menentukan nilai PDB subsektor ini. Apabila dilihat dari posisi subsektor ini yang berada pada urutan kedua setelah subsektor tanaman perkebunan, maka diharapkan kondisi ini tidak mengarah pada orientasi impor terhadap komoditas tanaman pangan untuk memenuhi kebutuhan dalam negeri. Hal ini mengingat bahwa secara geografis wilayah Indonesia memadai untuk menghasilkan produk tanaman pangan.

Tabel 1. Nilai PDB Sektor dan Subsektor

Pertanian ADHB Tahun 2014 di Indonesia (Miliar Rp)

\begin{tabular}{|c|c|c|c|c|c|}
\hline \multirow{2}{*}{$\begin{array}{l}\text { Sektor dan } \\
\text { Subacktor }\end{array}$} & \multicolumn{5}{|c|}{$\ln 14^{2 \ldots}$} \\
\hline & 1 & 11 & III & W & . \\
\hline 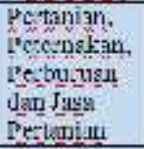 & $\begin{array}{r}265 \\
1.30 .20\end{array}$ & $\begin{array}{r}347 \\
171.90\end{array}$ & $\begin{array}{r}317 \\
66760\end{array}$ & $\begin{array}{r}2.25 \\
459.201\end{array}$ & $\begin{array}{r}1.8 .4 \\
944.4 \%\end{array}$ \\
\hline it. I:In arrian! & 106, & 4.5 & 47 & 54 & 74.3 \\
\hline pyrour & 903.20 & $2 \$ 2.00$ & 52250 & 111.50 & $9.52 .2 \%$ \\
\hline h. Tunsmrint & i7 & 42 & 42 & ifi & 159 \\
\hline 110ritkulums & 910551 & 6017 & i. & $291: 2$ & $5>0 \% ?$ \\
\hline 6. Tynaroun & 76 & $10 \%$ & 123 & 88 & 397 \\
\hline Pe:kebuniu & 152.20 & 401.90 & 20240 & $43 \% .70$ & 896.20 \\
\hline & 38 & 35 & .12 & is & 16) \\
\hline Decengkan & 920.80 & 730.90 & 70710 & 716.30 & 075.10 \\
\hline I Ill:as & 5 & 5 & 5 & 4 & 20 \\
\hline Pu-taman! & 26.3 .54 & 135,40 & 73420 & $-6,7.70$ & $500.8:$ \\
\hline
\end{tabular}

Sumber: BPS, 2014

Keterangan: ** data sangat sementara

Nilai PDB subsektor tanaman pangan diatas dapat dikonfirmasi dengan perkembangan kesejahteraan petaninya. Kesejahteraan petani ini dapat dicerminkan oleh perkembangan nilai tukar petani subsektor tanaman pangan (NTPP). Berdasarkan Tabel 2 dapat diketahui bahwa selama tahun 2008 - 2013 nilai NTPP baik di Provinsi Jawa Tengah maupun Indonesia cenderung meningkat. Hal ini memberi sinyal positif bahwa ada indikasi kesejahteraan petani relatif membaik dari tahun ke tahun.

Pola perkembangan NTPP di wilayah Provinsi Jawa Tengah tidak jauh berbeda dengan NTPP di Indonesia. Hal ini dimungkinkan karena Provinsi Jawa Tengah termasuk salah satu provinsi di Indonesia yang berperan penting terhadap ketersediaan produk tanaman pangan di Indonesia. Untuk itu, pemerintah pusat maupun pemerintah daerah di wilayah Provinsi Jawa Tengah perlu merumuskan kebijakan untuk minimal mempertahankan kesejahteraan petani. Hal ini ditujukan supaya ada insentif bagi para petani untuk meningkatkan produksi tanaman pangan.

Tabel 2. Nilai Tukar Petani Tanaman Subsektor Tanaman Pangan (NTPP) Provinsi Jawa Tengah dan Indonesia Tahun 2008 -

\begin{tabular}{|c|r|r|}
\hline \multicolumn{3}{|c}{2013} \\
Tahun & $\begin{array}{c}\text { NTPP } \\
\text { Jateng }\end{array}$ & $\begin{array}{c}\text { NTPP } \\
\text { Indonesia }\end{array}$ \\
\hline 2008 & 97,2 & 97,07 \\
\hline 2009 & 91,96 & 95,09 \\
\hline 2010 & 96,77 & 97,78 \\
\hline 2011 & 102,88 & 102,83 \\
\hline 2012 & 104,49 & 104,71 \\
\hline $2013^{1}$ & 105,33 & 104,62 \\
\hline
\end{tabular}

Sumber: BPS, 2014

Keterangan: ${ }^{1}$ data sementara

Data ketersediaan produk tanaman pangan seperti padi, jagung dan ubi kayu selama tahun 2008 - 2012 di Jawa Tengah menunjukkan indikasi peningkatan (BPS Jawa Tengah). Sebagai contoh pada tahun 2008 ketersediaan padi, jagung, dan ubi kayu masing-masing adalah 5,18 juta ton, 2,44 juta ton dan 2,83 juta ton. Sementara itu, pada tahun 2012 ketersediaan ketiganya masing-masing adalah 5,75 juta ton, 2,77 juta ton, dan 3,27 juta ton. Selain itu, perkembangan ketersediaan daging, telur, dan susu selama 
tahun 2008 - 2012 di Jawa Tengah cenderung meningkat. Pada periode tersebut ketersediaan susu cenderung lebih tinggi dibandingkan dengan ketersediaan daging dan telur, terutama tahun 2009 - 2012. Sebagai contoh pada tahun 2008 ketersediaan daging, telur, dan susu masing-masing adalah 265 ribu ton, 198 ribu on, dan 220 ribu ton. Sementara itu, pada tahun 2012 ketersediaan ketiga komoditas tersebut masing-masing adalah 337 ribu ton, 288 ribu ton, dan 498 ribu ton.

\section{Responden}

Responden penelitian ini adalah pedagang komoditas pangan di wilayah Provinsi Jawa Tengah. Metode penetapan/pemilihan sampel ditentukan dengan quota sampling. Hal ini berarti bahwa peneliti telah menetapkan jumlah tertentu (sebanyak 245 orang) sebagai responden.

Berdasarkan hasil survei dapat diketahui bahwa:

1) Responden berdasarkan jenis kelamin adalah sebanyak 57 orang responden laki-laki $(23,27 \%)$ dan 188 orang responden perempuan $(76,73 \%)$. Dengan demikian, total responden adalah 245 orang.

2) Sebaran responden adalah di 35 kabupaten/kota di wilayah Provinsi Jawa Tengah. Dengan demikian, masing-masing kabupaten/kota diwakili oleh 7 orang pedagang komoditas pangan.

3) Komoditas pangan yang menjadi fokus penelitian adalah Beras, Jagung, Kedelai, Daging Ayam, Daging Sapi, Ikan, dan Buahbuahan.

\section{Prioritas Faktor Penentu Daya Sa- ing Komoditas Pangan Jawa Te- ngah}

Identifikasi faktor yang akan diteliti sebagai faktor penentu daya saing komoditas pangan Jawa Tengah adalah Tingginya kebutuhan dalam negeri (HD), Aksesibilitasi komoditas pangan lokal (FA), Peran aktif pemerintah dalam pengawasan pangan (GI), Program Ketahanan dan Keamanan Pangan (FSS), Infrastruktur Pertanian (AI1), Investasi Sektor Pertanian (AI2). Keenam faktor tersebut akan dianalisis dengan tahapan, yaitu: variabel berpasangan (Tabel 3), normalized eigenvector (Tabel 4), consistency index (Tabel 5), dan consistency ratio (Tabel $6)$.

Tabel 3. Variabel Berpasangan

\begin{tabular}{|c|c|c|c|c|c|c|c|}
\hline & HD & FA & GI & FSS & AII & AI2 & Bobot \\
\hline $\mathrm{HD}$ & 0.05 & 0.03 & 0.03 & 0.04 & 0.05 & \begin{tabular}{|c|}
0.08 \\
\end{tabular} & 0.05 \\
\hline$\overline{\mathrm{FA}}$ & 0.10 & 0.06 & 0.03 & 0.04 & 0.06 & 0.09 & 0.06 \\
\hline GI & 0.23 & 0.26 & 0.16 & 0.11 & 0.12 & 0.19 & 0.18 \\
\hline FSS & 0.22 & 0.24 & \begin{tabular}{l|l}
0.24 \\
\end{tabular} & 0.18 & 0.11 & 0.19 & 0.20 \\
\hline AIl & 0.20 & 0.21 & 0.28 & 0.34 & 0.22 & 0.15 & 0.23 \\
\hline $\mathrm{AI} 2$ & 0.19 & 0.21 & 0.25 & 0.29 & 0.44 & 0.31 & 0.28 \\
\hline Total & 1.00 & 1.00 & 1.00 & 1.00 & 1.00 & 1.00 & 1.00 \\
\hline
\end{tabular}

Sumber: Data Primer (2016, diolah)

Berdasarkan tabel diatas dapat diketahui bahwa nilai preferensi antar variabel berdasarkan penilaian dari responden mempunyai bobot antara $0,05-0,28$ (total sama dengan 1 ). Nilai ini menjadi data awal untuk menentukan matriks dan nilai eigenvector. Penjelasan atas hasil perhitungan eigenvector dan normalized eigenvector dapat dilihat pada Tabel 4.

Tabel 4. Perhitungan Normalized Eigenvector

\begin{tabular}{|l|r|r|r|r|r|r|r|r|}
\hline & \multicolumn{1}{|l|}{ KE1 } & \multicolumn{1}{l}{ KE2 } & \multicolumn{1}{l}{ KE3 } & \multicolumn{1}{l}{ KE4 } & \multicolumn{1}{l}{ KE5 } & KE6 & Eigenvect & Normalize \\
\hline KE1 & 256.44 & 187.14 & 64.90 & 57.70 & 49.81 & 41.01 & 657.00 & 0.05 \\
\hline KE2 & 352.18 & 257.62 & 89.49 & 79.55 & 68.48 & 56.26 & 903.59 & 0.06 \\
\hline KE3 & 998.48 & 730.88 & 254.77 & 226.83 & 195.25 & 159.84 & 2566.06 & 0.18 \\
\hline KE4 & 1117.53 & 816.80 & 284.95 & 254.03 & 219.10 & 179.24 & 2871.65 & 0.20 \\
\hline KE5 & 1344.73 & 979.71 & 341.39 & 304.72 & 263.91 & 216.13 & 3450.58 & 0.24 \\
\hline KE6 & 1618.83 & 1178.70 & 409.09 & 364.40 & 315.68 & 259.62 & 4146.32 & 0.28 \\
\hline
\end{tabular}

Sumber: Data Primer (2016, diolah)

Keterangan: KE adalah nilai koefisien variabel

Tabel di atas memberikan hasil perhitungan eigenvector dan normalized eigenvector sebagai dasar pertimbangan pembobotan faktor penentu daya saing komoditas pangan dengan metode AHP. Nilai bobot AHP akan diperoleh dari hasil perhitungan nor- 
malized eigenvector yang masih akan diuji nilai konsistensinya. Hasil uji konsistensi dapat dilihat pada Tabel 5 dan 6. Berdasarkan kedua tabel tersebut dapat diketahui bahwa hasil pembobotan AHP adalah konsisten. Dengan demikian, nilai pembobotan AHP dapat digunakan sebagai acuan untuk melakukan pemeringkatan faktor penentu daya saing komoditas pangan Jawa Tengah.

Tabel 5. Perhitungan Consistency Index

\begin{tabular}{|l|r|}
\hline Lambda (Max.) & Nilai \\
\hline Row (Variable) 1 & 6.26 \\
\hline Row (Variable) 2 & 6.26 \\
\hline Row (Variable) 3 & 6.27 \\
\hline Row (Variable) 4 & 6.27 \\
\hline Row (Variable) 5 & 6.27 \\
\hline Row (Variable) 6 & 6.26 \\
\hline Average & 6.27 \\
\hline \multicolumn{2}{|l|}{ Consistency Index (CI) } \\
\hline CI & 0.05 \\
\hline
\end{tabular}

Sumber: Data Primer (2016, diolah)

Tabel 6. Perhitungan Consistency Ratio

\begin{tabular}{|l|l|l|l|l|}
\hline & & $\begin{array}{l}\text { Alons } \\
\text { o dan } \\
\text { Lamat }\end{array}$ & 1.24 & $\begin{array}{l}\text { Hasil: } \\
\text { Konsis } \\
\text { ten }\end{array}$ \\
$\begin{array}{l}\text { Stency } \\
\text { Ratio } \\
\text { (CR) }\end{array}$ & 0.043 & $\begin{array}{l}\text { a } \\
\text { denga } \\
\mathrm{n} \mathrm{n}=6\end{array}$ & & \\
\hline
\end{tabular}

Sumber: Data Primer (2016, diolah)

Berdasarkan perhitungan normalized eigenvector dan consistency ratio maka diperoleh hasil pemeringkatan faktor penentu daya saing komoditas pangan Jawa Tengah (Tabel 7). Hasil ini menunjukkan bahwa prioritas pertama penentu daya saing komoditas pangan Jawa Tengah adalah investasi sektor pertanian dengan nilai bobot AHP sebesar 0,28. Sementara itu, prioritas terakhir faktor penentu daya saing komoditas pangan adalah tingginya kebutuhan pangan dalam negeri dengan nilai bobot AHP sebesar 0,05.

Tabel 7. Pemeringkatan Faktor Penentu Daya Siang Komoditas Pangan Jawa Tengah

\begin{tabular}{|c|l|c|}
\hline No. & \multicolumn{1}{|c|}{ Faktor } & Bobot AHP \\
\hline 1 & Investasi Sektor Pertanian & 0.28 \\
\hline 2 & Infrastruktur Pertanian & 0.24 \\
\hline 3 & Program Ketahanan dan Keamanan Pangan & 0.20 \\
\hline 4 & Peran Aktif Pemerintah dalam Pengawasan Pangan & 0.18 \\
\hline 5 & Aksesibilitas Komoditas Pangan Lokal & 0.06 \\
\hline 6 & Tingginya Kebutuhan Pangan Dalam Negeri & 0.05 \\
\hline
\end{tabular}

Sumber: Data Primer (2016, diolah)

Hasil pemeringkatan faktor penentu daya saing komoditas pangan Jawa Tengah di atas memberikan arahan baik kepada pelaku usaha perdagangan komoditas pangan maupun lembaga-lembaga pemerintah bidang pangan/ekonomi. Ketersediaan investasi sektor pertanian yang terintegrasi antara hulu sampai hilir menjadi kunci penting perwujudan daya saing komoditas pangan dalam negeri. Faktor kedua yang juga menjadi kunci daya saing komoditas pangan adalah infrastruktur pertanian yang bisa menjamin integrasi bisnis dan kualitas produk termasuk efisiensi usaha.

\section{KESIMPULAN,IMPLIKASI, SARAN, DAN BATASAN}

Berdasarkan hasil analisis dapat disimpulkan bahwa: Perkembangan komoditas pangan Jawa Tengah dari tahun ke tahun cenderung meningkat. Hal ini diharapkan dapat menjadi sumber pemenuhan kebutuhan pangan lokal yang mencukupi dengan kualitas yang terstandar.

Prioritas faktor penentu daya saing komoditas pangan Jawa Tengah adalah: a) investasi sektor pertanian dengan bobot AHP sebesar 0,28; b) infrastruktur pertanian dengan bobot AHP sebesar 0,24 ; c) program ketahanan dan keamanan pangan dengan bobot AHP sebesar 0,20; d) peran aktif pemerintah dalam pengawasan pangan dengan bobot AHP sebesar 0,18; e) aksesibilitas komoditas pangan lokal dengan bobot AHP sebesar 0,06; dan f) tingginya kebutuhan pangan dalam 
negeri dengan bobot AHP sebesar 0,05 .

Sehingga rekomendasi dari penelitian ini adalah: Pelaku usaha sektor pangan perlu mempertahankan capaian produksi pangan yang sudah ada. Hal yang lebih baik dilakukan adalah meningkatkan produktivitas dan kualitas pangan lokal.

Pelaku usaha sektor pangan dan pemerintah daerah di wilayah Provinsi Jawa Tengah perlu mempertimbangkan prioritas faktor penentu daya saing komoditas pangan untuk mewujudkan komoditas pangan yang berdaya saing dan berkelanjutan. Kerjasama yang terintegral dan saling menguntungkan antara pelaku usaha dan pemerintah dalam mewujudkan daya saing komoditas pangan perlu dilakukan. Misalnya adalah menjaga lahan untuk kelestarian ketersediaan pangan, memperbaiki distribusi komoditas pangan baik dengan pendekatan toko tani maupun teknologi informasi pangan di berbagai pasar dan statistik pangan oleh pemerintah daerah, dan pengawasan kualitas dan kesehatan pangan oleh lembaga pemerintah yang berwenang.

\section{DAFTAR PUSTAKA}

Aiginger, Karl, Susanne BärenthalerSieber and Johanna Vogel. (October 2013). Competitiveness under New Perspectives. Working PaperNo 44. European Commision.

Ambastha, Ajitabh and K. Momaya. (2004).Competitiveness of Firms: Review of Theory, Frameworks, and Models. Singapore Management Review. Volume 26 No. 1.

Bodini, Antonella and Raffaele Zanoli. (September 2009).Competitive Fac- tors of The Agro-Food E-Commerce. The 113th EAAE Seminar "A resilientEuropean food industry and food chain in a challenging world", Chania, Crete,Greece.

Bohari, Abdul Manaf, Cheng Wei Hin and Nurwahida Fuad. (2013). The Competitiveness of Halal Food Industry in Malaysia: A SWOT -ICT Analysis. Malaysia Journal of Society and Space9issue 1 (1 - 9).

Bris, Arturo and José Caballero. (2016). Revisiting the Fundamentalsof Competitiveness:A Proposal. IMD World Competitiveness Center.

Cahyadin, Malik dan Dyah Maya Nihayah. (2014). Model Tataniaga Komoditas Kebutuhan Pokok Di Indonesia. Artikel di dalam Buku Seri Monograf dengan Tema Meneropong Pembangunan Ekonomi Indonesia. Surabaya: FBE UBAYA dan FORDES ISEI Cabang Surabaya.

Cuevas, Roberto. (2004). Food Engineering, Quality and Competitiveness in Small FoodIndustry Systems with Emphasis on Latin America and The Caribbean. Rome: FAO.

Eskandari, Meysam Jafari. et.al. (2015).Factors Affecting The Competitiveness of The Food Industry by Using Porter's Five Forces Model Case Study in Hamadan Province, Iran. $\mathrm{Jo}$ urnal of Asian Scientific Research 5(4) pp.185-197.

Fischer, Christian. (2002).Identifying Key Factors Affecting Success inInternational Food Product Markets. Justus-Liebig-Universität Giessen. 
Halmai, Peter and Andrea Elekes. (2002). Factors Determining EU-Competitiveness of the Hungarian Agriculture: Trade Policy Approach. Paper prepared for presentation at the Xth EAAE Congress 'Exploring Diversity in the European Agri -Food System', Zaragoza (Spain), 28-31 August.

Harini, Yunastiti Purwaningsih, Malik Cahyadin, dan Emi Widiyanti. (2015). Model Tata Niaga Komoditas Tanaman Pangan di Provinsi Jawa Tengah Menuju Ketahanan Pangan Daerah. LPPM UNS.

Ketels, Christian. (March 2016). Review of Competitiveness Frameworks. National Competitiveness Council of Dublin.

Moïsé, E. et al.(2013). Estimating the Constraints to Agricultural Trade of Developing Countries. OECD Trade Policy Papers, No. 142, OECD Publishing. http://dx.doi.org/10.1787/5k4c9kwfdx 8r-en

OECD. (2011).Fostering Productivity and Competitiveness in Agriculture, OECDPublishing. http://dx.doi.org/10.1787/9789264166 $\underline{820-e n}$

Saaty, Thomas L. (2008). Decision Making with the Analytic Hierarchy Process. Int. J. Services Sciences, Vol. 1, No. 1 pp. 83-98.

Seguin, Bob and Janalee Sweetland. (February 2014). Drivers of CanadianFood Processing Competitiveness: Macro Factors and Micro Decisions. CAPI and GMC.
Siudek, Tomasz and Aldona Zawojska. (2014). Competitiveness in The Economic Concepts, Theories and Empirical Research. Oeconomia 13 (1) pp. 91-108.

Vuković, Darko, Ana Jovanović, and Mališa Đukić. (2012).Defining Competitiveness Through The Theories ofNew Economic Geography and Regional Economy. J. Geogr. Inst. Cvijic. 62(3) pp. 49-64. 